\title{
Extractive Dearomatization of Naphthalane Oil Fraction with Ionic Liquid and -N-Methyl-2-Pyrrolidone
}

Vagif M. Abbasov, Leylufer I. Aliyeva*, Parvana A. Movsumova, Almaz M. Tagieva, Gultakin A. Najafova, Arzu E. Alizade, Bekir A. Aliyev, Fakhraddin F. Mammadov Yu. H. Mammadaliev Institute of Petrochemical Processes, National Academy of Sciences of Azerbaijan, AZ1025 Baku, Azerbaijan, E-mail: ipcp@baku-az.net

*Corresponding Author, E-mail: leylufer-ipcp@rambler.ru

\begin{abstract}
In the article are given an analysis of the results of researches carried out for the purpose of selective treatment of the Naphthalane oil fraction boiling at $260-340^{\circ} \mathrm{C}$ with ionic liquid (IL) -morfolinphormiate synthesized on the basis formic acid + morpholine and - N-methyl-2-pyrrolidon (N-MP) and as an extractant. The aim is to remove poisonous components sulfur compounds and toxic carcinogenic polynuclear aromatic hydrocarbons in order to improve therapeutic properties of Naphthalane oil cut. For this purpose we have used extraction method. On the basis of the conducted researches the role of -N-methyl-2-pyrrolidone and IL-morpholinephormiatee in extraction conditions have been determined in selective treatment of Nafthalan oil, according to the results of spectral analysis residual amount of aromatic hydrocarbons decreased from $18.5 \% \mathrm{wt}$ accordance to $2 \%, 1.5 \%$. As well as the amount of sulphur decreased from $0.0354 \%$ to $0.010 \%$, $0.011 \%$ and $0.019 \%$.

In the next stage the treated raffinates with $\mathrm{N}$-methyl-2-pyrrolidone has been purified on silica. In a result amount of aromatic hydrocarbons drastically decrease to be $0.07 \%$ and $0.02 \%$. As a result we aquire transparency and at the same time the percentage amount of aromatic hydrocarbons drastically decreased from $2 \%$ to $0,07 \%, 1.5 \%$, to $0.02 \%$. Raffinates obtained in a 2-4 stage dearomatization with N-MP and IL. Raffinate are measured on NMR, UV and IR spectral analysis.
\end{abstract}

Keywords:-Naphthalane oil; dearomatization; extraction; extractant; selective treatment; raffinate; ionic liquid; carcinogenic coumpound; silica.

\section{Council for Innovative Research}

Peer Review Research Publishing System

\section{Journal: Journal of Advances in Chemistry}

Vol 11, No. 6

editorjaconline@gmail.com, www.cirjac.com 


\section{INTRODUCTION}

As it is known there are a number of oil fields both on the land and also in the Caspy sea basin of Azerbaijan. Some of them has a special pecularities, including Naphthalane oil. Naphthalane oil is differed from other oils in its significancy, therapeutic effect and physico-chemical properties. It doesn't contain paraffin hydrocarbons and petroleum fraction, has a high beginning of boiling point (190-2000C). Naphthalane oil therapeutic effect is connected to the naphthen hydrocarbons contained in it.

Beside the biological active naphthene hydrocarbons also poisonous components in the content of Naphthalane oil were determined, that have negative impact on its treatment properties. These are asphaltenes, resins, naphthenic acids and polynuclear aromatic hydrocarbons, sulfur compounds [1,2]. As mentioned Naphthalane oil contains toxic components and toxic carcinogenic polynuclear aromatic hydrocarbons are considered the most dangerous ones.

So, the most dangerous carsinogens are dimethyltetraphenes, dibenzpirenes, antracenes.

As the result of scientific researches relative carcinogenic activity of eight polynuclear aromatic hydrocarbons have been determined; carcinogenic properties have been detected in 3,4-benzpyrene > anthracene > 2,3-benzfluorentene > ortophenylenpyrene > 11,12- benzfluorantene, and 10,11- benzfluorentene, 1,2 benzpyrene and 1,12- benzperylene [3].

But depending on boiling temperature the amount of polynuclear aromatic hydrocarbons in Naphthalane oil fractions varies (from 2000C - up to 4500C). Thus, by increasing of boiling temperature, the amount of aromatic hydrocarbons increases. Benzene, naphthalene, phenantrene, benzofluorene, chryzene, anthracene, 1,2-benzantracene, 3,4benzphenantrene, pyrene aromatic hydrocarbons were detected in all fractions of naphthalene oil.

As seen, if Naphthalane oil is used naturally for the purpose of therapeutic, it is great importance conducting researches related to its purification. Thus, in study of structural-group composition of Naphthalane oil the extensive researches has been carried out, refining technologies from asphaltenes, resins, naphthenic acids, sulphur compounds, mainly polynuclear aromatic hydrocarbons were developed by using acid-contact, hydrogenation, hydrotreatment methods. However, the processes requiring the use of many solvents, adsorbents, acid, high pressure, is not efficient ecological and economically and there is not use area of wastes produced from purification processes in industry. So, hydrogenation and hydrotreatment processes accompanied by the loss of high-energy could not be considered the most efficient treatment method of Naphthalane oil.

Should be specifically noted that, as a result of creating perspective treatment technology of therapeutic Naphthalane oil and production of naphthenic hydrocarbons it is possible to use this in the treatment of some diseases (eye diseases, gynecological diseases, burns, open wounds, and nose-throat diseases etc.) and cosmetic industry [4]. In the recent years for purification of oil fraction used environmentally ionic liquid [5-7]. The aim of this work is to study the capabilities of N-methyl-2-pyrrolidone and ionic liquid for the dearomatization and desulphurization of Naphthalane oil fraction by extraction method.

\section{EXPERIMENTAL PROCEDURE}

In this view we partially realized purification process by using Naphthalane oil fraction $\left(d_{-}^{20}-0.8900 \mathrm{q} / \mathrm{sm} 3\right.$, $\eta_{D}^{20}$. $1.4870, \mathrm{M}-274$, amount of aromatic $\mathrm{h} / \mathrm{c}$, by sulfurization method, $\%-18.5$ ) boiling at $260-340^{\circ} \mathrm{C}$. We have detected benzene, naphthalene, phenantrene, benzofluorene, chryzene, anthracene, 1,2-benzantracene/3,4-benzphenantrene, pyrene aromatic hydrocarbons in Naphthalane oil fraction boiling at $260-340^{\circ} \mathrm{C}$

Morpholine and formic acids are used for the synthesis of the morpholinephormiate-containig ionic liquid. Physical-chemical properties of the morpholine and formiat acid used for the synthesis of ionic liquid (IL) are compatible to the references.

Morpholine and formic acid boiling points allows high yield synthesis of the corresponding IL. So, there is no synthesis evaporation and as a result of it no loss. Besides the high density 1000.5 and $1219.6 \mathrm{~kg} / \mathrm{m} 3 \mathrm{both}$ of two chemicals also testifies to high density of the ionic liquid which will be synthesized from them. Phase separation after the extraction depends on the difference of the densities and higher density of solvent than density of oily fraction is one of the factors leading to enough less residue amount in the raffinate solution.

Laboratory synthesis of morpholinephormiate-containing ionic liquid is carried out as below.

IL synthesis on the basis of formic acid and morpholine is carried out at the same ratios (molar), 60-700C temperature during $1.5 \mathrm{~h}$. At first calculated amount of morpholine $(87.12 \mathrm{~g})$ is poured to the reaction flask. Then formic acid $(52.94 \mathrm{~g})$ is added on the morpholine gradually by mixing. The formic acid of $85 \%$ is used in the reaction.

The fraction boiling above $1350 \mathrm{C}$ is used as an IL. Otherwise non-reactive morpholine can be remained at $1350 \mathrm{C}$ boiling fraction. 
Here is the reaction general scheme:

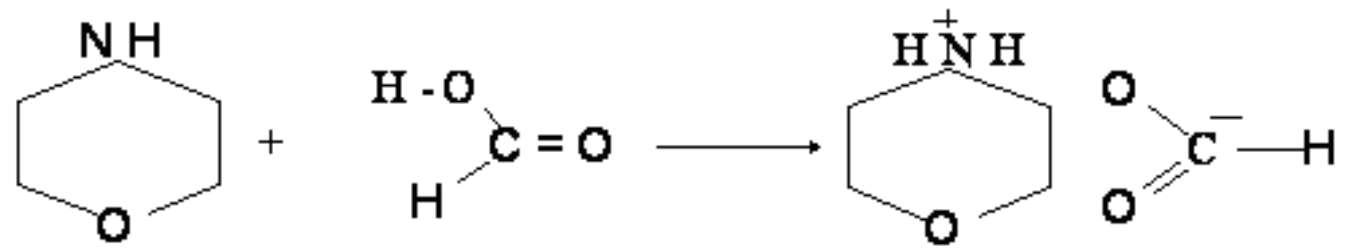

Influences of different factors (temperature, molar ratio of components, reaction duration) on the IL synthesis have been studied and corresponding optimal conditions have been determined. The components same ratios (molar), 60-700C temperature and $1.5 \mathrm{~h}$ duration are considered the optimal conditions for IL synthesis. The optimal yield has been got by different temperature syntheses of morpholine-containing IL synthesized on the basis of formic acid and morpholine. The IL yield obtained at the optimal conditions is $95.07 \%$ (mas.). The proses general material balance has been compiled according to the optimal conditions researched. Table 1 presents material balance of obtaining of morpholinephormiatecontaining IL:

Table 1. Material balance of morpholinephormiate-containing IL

\begin{tabular}{|l|c|c|}
\hline Taken: & \multicolumn{2}{|c|}{ Mass } \\
\cline { 2 - 3 } & $\mathrm{g}$ & 62.20 \\
\hline morpholine & 87.12 & 37.80 \\
\hline formic acid (85\%) & 52.94 & 100 \\
\hline Obtained: & 140.06 & 95.07 \\
IL-morpholinephormiate & 133.15 & 4.93 \\
water & 6.91 & 100 \\
\hline Total & & 140.06 \\
\hline
\end{tabular}

As Table 1 presents, morpholine-containing IL synthesized on the basis of formic acid and morpholine amounts to $95.07 \%$ (mas.), but water separated from the mixture $-4.93 \%$. Thus, the water separated from the mixture is the same one in the containing of the formic acid (15\%).

It's important to note that synthesized morpholinephormiate-containing IL has higroscopicity. The occurence of $0.047 \%$ (mas.) water absorption has been observed while keeping morpholine-containing IL at $20-25^{\circ} \mathrm{C}$ in the open air for 90 hours.

IL obtained on the basis of formic acid and morpholine is transparent white viscous liquid.

The morpholinephormiate-containing IL obtained has all quality properties characterized for IL type salts, such as liquid state at very wide temperature limits $\left(-5^{\circ} \mathrm{C}-250^{\circ} \mathrm{C}\right)$, low vapor pressure, high and selective solvent ability, thermal stability (more than $300^{\circ} \mathrm{C}$ ).

Low viscousity of morpholinephormiate-containing IL provides ideal mixing with oil fractions during extraction. This pecularity causes its easier connection with the aromatic hydrocarbons and sulfur compounds in the containing of oil fractions during extraction proses.

Table 2. Physical-chemical properties of morpholine-containing IL

\begin{tabular}{|l|c|}
\hline \multicolumn{1}{|c|}{ Properties } & Values of properties \\
\hline Density at $20^{\circ} \mathrm{C}, \mathrm{kg} / \mathrm{m}^{3}$ & 1135 \\
\hline Coefficient $n_{D}^{20}$ & 1.4850 \\
\hline Boiling point, ${ }^{\circ} \mathrm{C}$ & - \\
\hline Melting point, ${ }^{\circ} \mathrm{C}$ & -5 \\
\hline Critical point, ${ }^{\circ} \mathrm{C}$ & 426 \\
\hline Critical pressure, Mpa & 5.24 \\
\hline
\end{tabular}




\begin{tabular}{|c|c|}
\hline Molecular weight & 133 \\
\hline Freezing point, ${ }^{\circ} \mathrm{C}$ & -4.5 \\
\hline${\text { Kinematic viscosity, } \mathrm{mm}^{2} / \mathrm{s}:}$ \\
at $20^{\circ} \mathrm{C}$ & 9.18 \\
$16^{\circ} \mathrm{C}$ & 106 \\
\hline Flash point, ${ }^{0} \mathrm{C}$ & $1.11 \cdot 10^{-2}$ \\
\hline Specific electrical conductivity, Pcm & \\
\hline
\end{tabular}

One of the important requirements for the solvents is a safety problem that is met positively in morpholinephormiatecontaining IL.

Morpholinephormiate-containing IL obtained on the basis of $\mathrm{N}$-methyl-2-pyrrolidon and formic acid + morpholin is used as an extractant for the purification of Naphthalane oil. For this purpose extraction of selected extractants - Nmethyl-2-pyrrolidon (N-MP) and morpholine-containing IL is carried out by Naphthalane oily fraction. For the definition of the proses optimal conditions intensive mixing of the components is carried out stage-by-stage in three-necked flask - at room temperature and $60^{\circ} \mathrm{C}$ by N-MP, but at $50-90^{\circ} \mathrm{C}$ by IL-morpholinformiat, by N-MP : Naphthalane oil fraction (at room temperature, $20^{\circ} \mathrm{C}$ - from 1:0.5 1:2.5 mas.; $60^{\circ} \mathrm{C}$ - from 1:0.5 1:3 mas.), and at different ratios by ILmorpholinephormiate:Naphthalane oil fraction (from 1:1 1:2, mas.), by N-MP extractant for 30 minutes contacting duration, by IL-morpholinephormiate about an hour. Then the mixture obtained is kept in an alternative funnel until absolute separation of raffinate and extractant solutions phases. The bottom layer is the extract-, but the top layer is raffinate solutions.

The raffinate and extract quality properties and structural-group compositions are studied by the modern physicalchemical analysis methods after the separation of them from the solvent by corresponding methods.

It is carried out NMR-, UV- and IG-spectral analyses of the raffinate obtained by the fraction purification through preliminary and selecting extractant - N-methyl-2-pyrrolidon. Besides, the raffinate purified through the extractant - Nmethyl-2-pyrrolidon has been passed through the silica produced by Sigma-AldRICH Company of Germany.

UV-analyses have been carried out by UV 6850 UV/Vis (Jenway company) spectrophotometer, at 190-350 nm spectral area, room temperature. The samples spectra have been taken in different concentrations $\left(\mathrm{c}_{1}-10.75 \mathrm{~g} / \mathrm{ml}, \mathrm{c}_{2}-2.52\right.$ $\mathrm{g} / \mathrm{ml}, c_{3}-0.40 \mathrm{~g} / \mathrm{ml}$ ) quartz bathtubs of $1.9 \mathrm{~cm}$ thickness, benzene and polycyclic aromatic hydrocarbons amounts have been defined by the help of izooctane solvent .

IR-spectrum of the fraction boiling at $260-340^{\circ} \mathrm{C}$ has been taken at $600-4000 \mathrm{~cm}^{-1}$ wavelength range by ALPHA IRFurye spectrometer of BRUKER company of Germany and the following absorption bands have been observed:

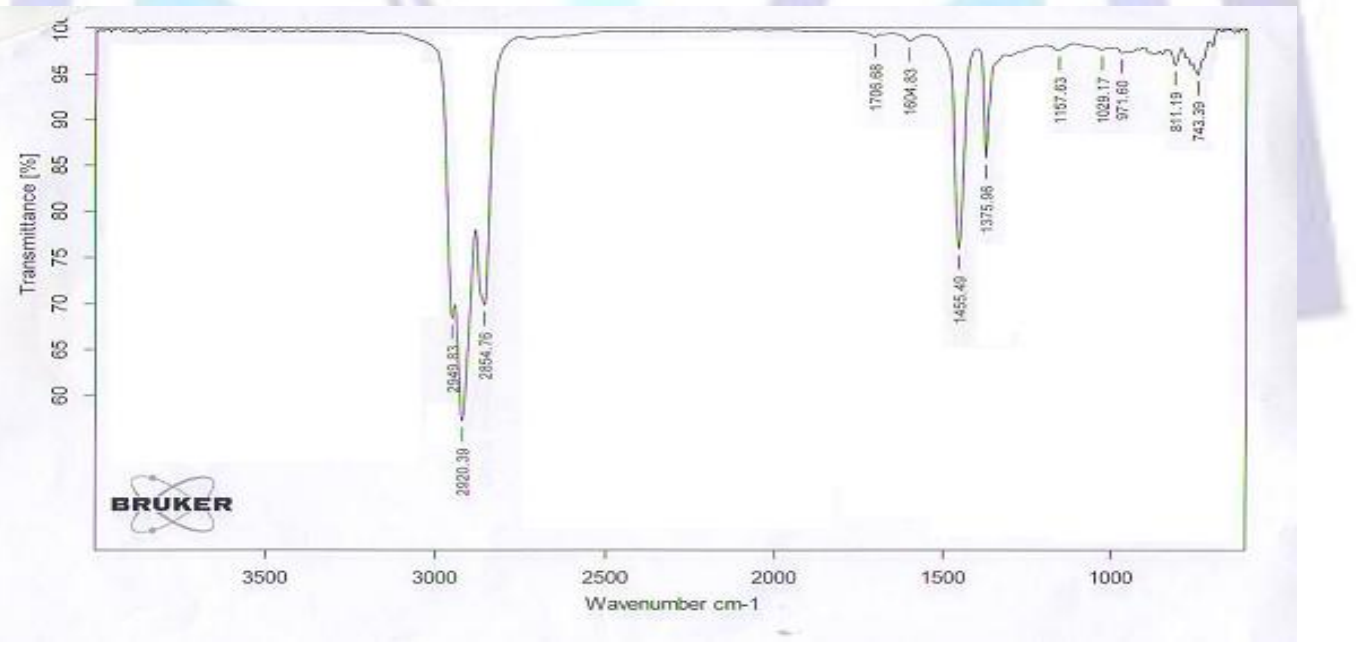

Figure 1. IR-spectrum of the fraction boiling at $260-340^{\circ} \mathrm{C}$

743 və $811 \mathrm{~cm}^{-1}$

$1455,2920,2940 \mathrm{~cm}^{-1}$

$1375,2854 \mathrm{~cm}^{-1}$

$1604 \mathrm{~cm}^{-1}$

$1157 \mathrm{~cm}^{-1}$

$1709 \mathrm{~cm}^{-1}$ substituted aromatic hydrocarbon;

$\mathrm{CH}_{2}$ group $\mathrm{C}-\mathrm{H}$ bonds' deformation and valence dances;

$\mathrm{CH}_{3}$ group $\mathrm{C}-\mathrm{H}$ bonds' deformation and valence dances

$\mathrm{C}=\mathrm{C}$ connection of aromatic hydrocarbons;

C-O bond;

$\mathrm{C}=\mathrm{O}$ bond; 

$1029 \mathrm{~cm}^{-1}$
$\mathrm{OH}$ bond;
$971 \mathrm{~cm}^{-1}$
$\mathrm{COOH}$ group $\mathrm{O}-\mathrm{H}$ bond

NMR spectra have been taken by Furye spectrometer (production of "Bruker" company) of $300.18 \mathrm{MHs}$ frequency working in pulsed mode at room temperature. Deuterium acetone has been used as a solvent.

\section{RESULTS AND DISCUSSION}

Results of selective purification of $260-340^{\circ} \mathrm{C}$ fraction of Naphthalane oil by N-MP and IL are presented in Table 3-5.

Table 3. Stage-by-stage selective purification of Naphthalane oil by N-methyl-2-pyrrolidon as an extractant (at $20^{\circ} \mathrm{C}$ temperature, every stage duration is 30 minutes)

\begin{tabular}{|c|c|c|c|c|c|c|c|c|c|c|}
\hline & 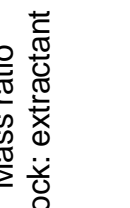 & $\begin{array}{l}\frac{\bar{\Phi}}{0} \\
\frac{\varrho}{E}\end{array}$ & $\begin{array}{l}\text { 듬 } \\
\frac{0}{0} \\
\frac{1}{3} \\
\frac{\bar{\sigma}}{\bar{J}}\end{array}$ & & $\begin{array}{l}\text { ¿̊ } \\
\frac{0}{0} \\
\frac{0}{2}\end{array}$ & 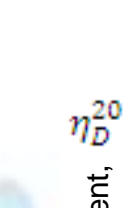 & $\begin{array}{l}d_{4}^{20} \\
{ }^{0} \\
\text { है }\end{array}$ & $\begin{array}{l}0 \\
0 \\
0 \\
+ \\
+ \\
\text { ग } \\
0 \\
0\end{array}$ & & \\
\hline & $\begin{array}{l}0 \\
8 \\
\Phi \\
\end{array}$ & \begin{tabular}{l}
0 \\
\multirow{0}{*}{} \\
ஸे
\end{tabular} & $\begin{array}{l}\text { ㅇ } \\
\text { ฮั }\end{array}$ & $\begin{array}{l}\frac{\pi}{\mathbb{N}} \\
\frac{\mathbb{U}}{0}\end{array}$ & 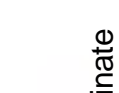 & 可 & $\stackrel{\substack{0 \\
\frac{1}{0}}}{n}$ & हE & 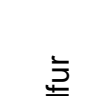 & 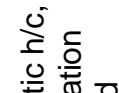 \\
\hline$\overline{0}$ & 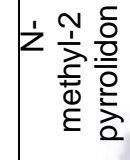 & & 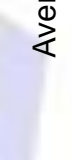 & $\begin{array}{l}\text { 爻 } \\
\text { (n) }\end{array}$ & $\stackrel{\mathscr{N}}{\simeq}$ & & & 产 & S & 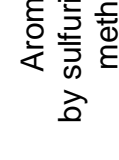 \\
\hline 1 & 0.5 & 1 & 272 & 54.34 & 93.63 & 1.4760 & 0.8828 & 5.14 & 0.022 & 12 \\
\hline 1 & 1 & 2 & 272 & 196 & 84.00 & 1.4760 & 0.8827 & 5.20 & 0.017 & 10 \\
\hline 1 & 2 & 4 & 272 & 223.99 & 76.01 & 1.4750 & 0.8825 & 5.28 & 0.014 & 0 \\
\hline 1 & 2 & 2 & 270 & 223.83 & 76.17 & 1.4740 & 0.8815 & 5.35 & 0.010 & 0 \\
\hline 1 & 2.5 & 5 & 268 & 190.1 & 59.90 & 1.4719 & 0.8807 & 5.40 & 0.012 & 0 \\
\hline
\end{tabular}

Table 4. Stage-by-stage selective purification of Naphthalane oil by N-methyl-2-pyrrolidon (at $60^{\circ} \mathrm{C}$ temperature, every stage duration is 30 minutes)

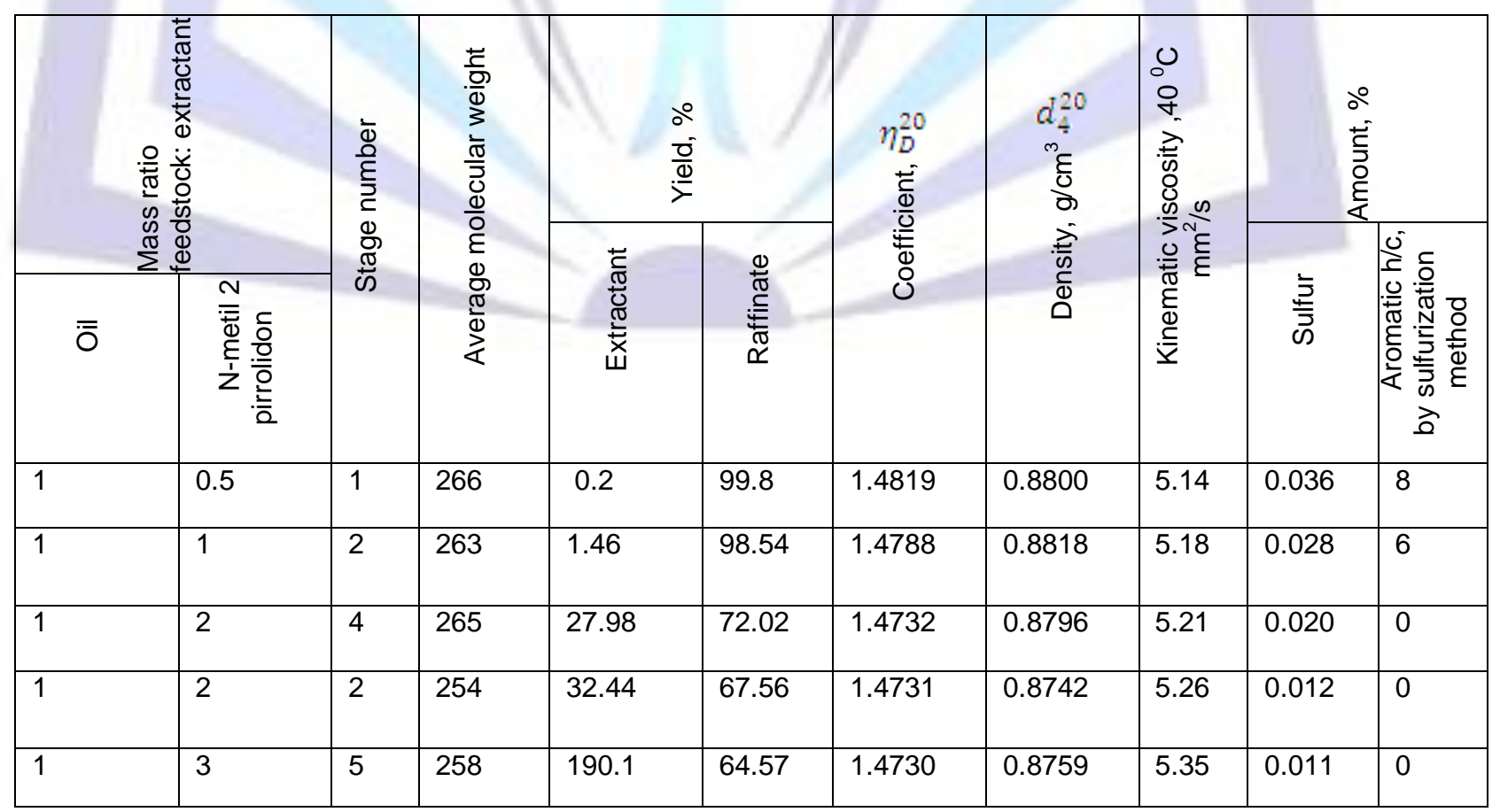


Table 5. Selective purification of Naphthalane oil by IL - morpholinephormiate(3 staged, every stage duration is 60 min.)

\begin{tabular}{|c|c|c|c|c|c|c|c|c|c|c|}
\hline \multicolumn{2}{|c|}{ 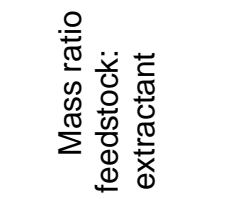 } & \multirow[b]{2}{*}{ 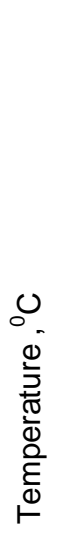 } & \multirow{2}{*}{ 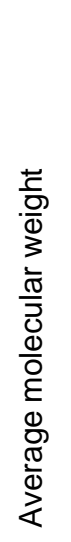 } & \multicolumn{2}{|c|}{$\begin{array}{l}\stackrel{0}{0} \\
\frac{i}{0} \\
\frac{0}{2}\end{array}$} & \multirow{2}{*}{ 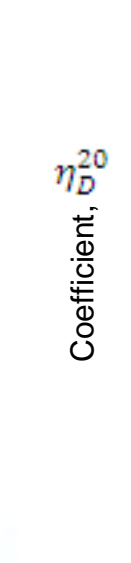 } & \multirow{2}{*}{ 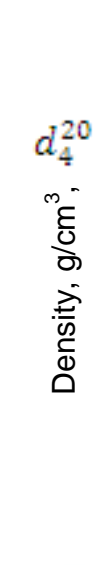 } & \multirow{2}{*}{ 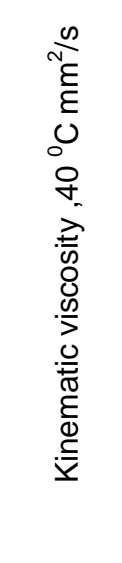 } & \multicolumn{2}{|c|}{ 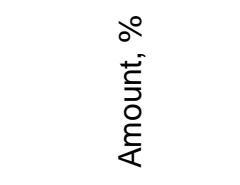 } \\
\hline$\overline{\overline{0}}$ & 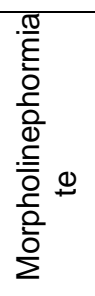 & & & 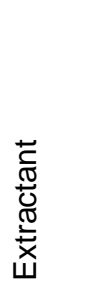 & 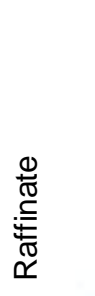 & & & & $\begin{array}{l}\frac{\grave{J}}{5} \\
\text { 心 }\end{array}$ & 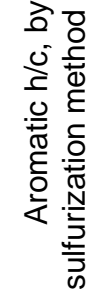 \\
\hline 1 & 1 & 50 & 250 & 10.49 & 89.51 & 1.4781 & 5.01 & 0.8749 & 0.022 & 6 \\
\hline 1 & 1 & 60 & 250 & 14.06 & 85.94 & 1.4778 & 5.28 & 0.8750 & 0.014 & 8 \\
\hline 1 & 2 & 60 & 250 & 16.08 & 83.92 & 1.4761 & 5.19 & 0.8751 & 0.013 & 6 \\
\hline 1 & 1 & 70 & 250 & 15.76 & 84.24 & 1.4770 & 5.20 & 0.8751 & 0.020 & 8 \\
\hline 1 & 2 & 70 & 250 & 17.32 & 82.68 & 1.4781 & 5.07 & 0.8751 & 0.019 & 2 \\
\hline 1 & 1 & 80 & 250 & 14.83 & 85.17 & 1.4781 & 5.10 & 0.8751 & 0.024 & 4 \\
\hline 1 & 2 & 80 & 250 & 15.45 & 84.55 & 1.4775 & 5.20 & 0.8751 & 0.018 & 8 \\
\hline
\end{tabular}

There are not aromatic hydrocarbons in the last 3 samples of Table 3 and Table 4 (sulfurization method, $98.6 \% \mathrm{H}_{2} \mathrm{SO}_{4}$ ). We have taken IR-, UV- and NMR-spectra of 5 staged raffinates at 1:2.5 from Table 3 and 5-staged raffinates at 1:3 from Table 4. IR-spectrum of 1:2.5 sample (Table 3) is presented on Figure 2, and 1:3 sample - on Figure 3.

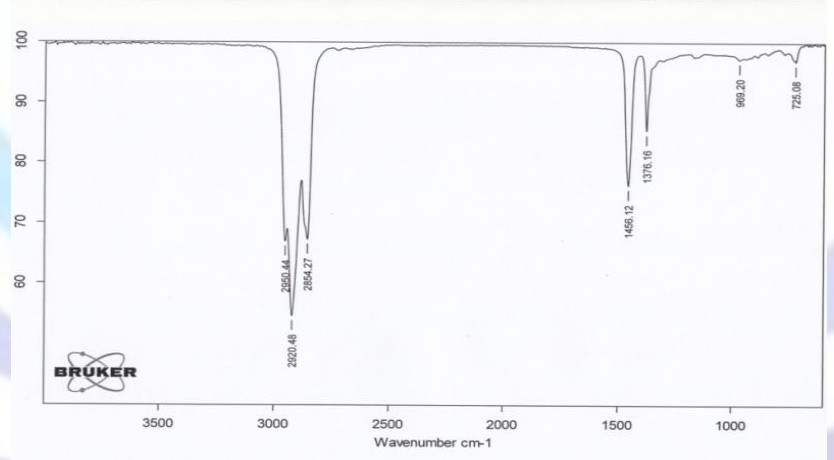

Figure 2. IR-spectrum of Naphthalane oil fraction purified at room temperature by N-MP

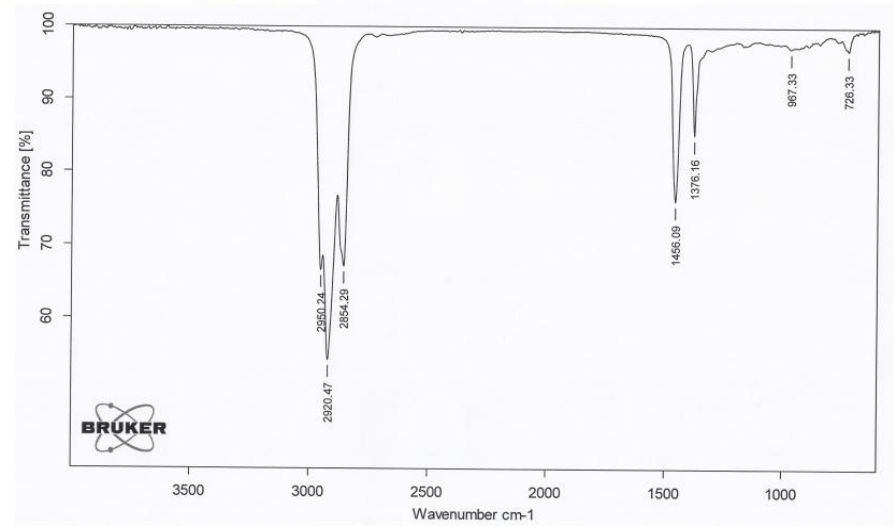

Figure 3. IR-spectrum of Naphthalane oil fraction purified by N-MP at $60^{\circ} \mathrm{C}$ 
IR-spectra of Naphthalane oil fraction (boiling at $260-340^{\circ} \mathrm{C}$ ) raffinate purified through selective extractant and adsorbent have been studied and determined that there isn't absorbent bands characteristic for aromatic hydrocarbons $\left(1604 \mathrm{~cm}^{-1}\right)$ on the raffinate spectrum. We have also carried out UV-spectral analyses of these samples. We have observed monoand polycyclic aromatic hydrocarbons corresponding to benzenes $1.57 \%$ and 0.94 ; naphthalenes $-0.39 \%$ and 0.33 ; phenantherenes $-0.07 \%$ and $0.11 \%$; benzophuluarenes $-0.02 \%$ and $0.03 \%$; chrizenes $-0.05 \%$ and $0.07 \%$; antrasenes $-0.007 \%$ and $0.01 ; 1,2$ benzantrasenes / 3,4 benzphenantherenes $-0.02 \%$ and $0.05 \%$ in the sample (Table 3 and 4 ) purified by the extractant - N-methyl-2-pyrrolidon. Percentage amount of the above listed is $2.13 \%$ and $1.5 \%$. Only mononuclear aromatic hydrocarbons (benzenes $-0.07 \%$ and $0.02 \%$ ) are observed after the purification by an adsorbent.

As a result we have taken NMR-spectra of Naphthalane oil fraction preliminary and after purification samples (Table 3 and 4). The most important parameters values of hydrocarbon composition observed on NMR-spectra are presented in Table 6.

Physical-chemical and NMR-spectroscopy characteristics of the raffinate of Naphthalane oil fraction boiling at $260-340^{\circ} \mathrm{C}$, obtained after the purification by selective solvent - N-methyl-2-pyrrolidon (N-MP) and silica are presented in Table 6.

Table 6. Physical-chemical and NMR-spectroscopic characteristics

\begin{tabular}{|c|c|c|c|c|c|c|c|c|c|c|c|c|}
\hline \multirow{2}{*}{$\begin{array}{c}\text { Fraction } \\
\mathrm{s} \\
\text { Number }\end{array}$} & \multirow{2}{*}{ 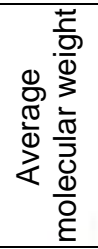 } & \multicolumn{5}{|c|}{$\begin{array}{l}\text { Hydrogen distributiion according } \\
\text { for the structural groups, } \%\end{array}$} & \multicolumn{2}{|c|}{$\begin{array}{l}\text { The number of } \\
\text { the rings }\end{array}$} & \multicolumn{3}{|c|}{$\begin{array}{c}\text { Carbon atoms number } \\
\text { in molecular } \\
\text { fragments, } \%\end{array}$} & \multirow{2}{*}{$\begin{array}{c}\text { Aromaticity } \\
\mathrm{f}_{\mathrm{a}}\end{array}$} \\
\hline & & $\mathrm{H}_{\mathrm{A}}$ & $\mathrm{H}_{\alpha}$ & $H$ & & $\mathrm{H}_{\gamma}$ & $\mathrm{K}_{\mathrm{A}}$ & $\mathrm{K}_{\text {saturated }}$ & $\mathrm{C}_{\mathrm{A}}$ & $\mathrm{C}_{\mathrm{N}}$ & $\mathrm{C}_{\text {alk }}$ & \\
\hline I & 292.0 & 2.8 & 3.2 & (15.5) & 35.9 & 42.6 & 0.40 & 3.73 & 17.0 & 58.6 & 24.4 & 0.17 \\
\hline II & 275.0 & 1.2 & 2.1 & $(17.0)$ & 34.2 & 45.5 & 0.05 & 3.29 & 2.0 & 73.3 & 24.7 & $\sim 0.02$ \\
\hline III & 249.0 & 0.5 & 0.9 & (19.6) & 38.8 & 40.2 & - & 3.07 & 0.07 & 77.1 & 22.9 & $7 \cdot 10^{-4}$ \\
\hline IV & 246.5 & 0.2 & 0.7 & (20.3) & 38.1 & 40.7 & - & 3.09 & 0.02 & 79.4 & 20.3 & $2 \cdot 10^{-4}$ \\
\hline
\end{tabular}

$H_{\beta}^{*}$ - indices of naphthenic structures are given in the brackets

$H_{A}, H_{\alpha}, H_{\gamma}$ - relative share of hydrogen atoms in the different structural groups (aromatic, alkyl and etc.)

$\mathrm{K}_{\mathrm{a}}$ and $\mathrm{K}_{\text {saturated- }}$ aromatic and saturated cycles number

$\mathrm{C}_{\alpha}, C_{\beta}, C_{a l k .}$ - carbon atoms share in aromatic, naphthene and alkyl fragments, correspondingly

$\mathrm{f}_{\alpha}$ - aromaticities of the fractions

As it is presented, the main part of hydrogen atoms are in the saturated structures of the average molecules, but the rest $-2-3 \%$ are in aromatic rings in the samples studied by us. And it is compatible to low aromaticity of molecules. The fractions structural parameters have been calculated by the method [8].

This method allows definition of aromatic $\left(\mathrm{K}_{\mathrm{A}}\right)$ and saturated $\left(\mathrm{K}_{\text {saturated }}\right)$ rings numbers in carbon and hydrogen atoms aromatic $\left(\mathrm{H}_{\mathrm{A}}\right.$ and $\left.\mathrm{C}_{\mathrm{A}}\right)$, naphthene $\left(\mathrm{C}_{\mathrm{N}}\right)$ and alkyl $\left(\mathrm{C}_{\text {alk. }}\right)$ structures of the average molecules of the fractions and also the share of terminal methyl groups $\left(\mathrm{H}_{\gamma}\right)$ in alkyl rings of hydrogen atoms.

We have also estimated the share of alkyl fragments $\left(-\mathrm{CH}_{3},-\mathrm{CH}_{2},-\mathrm{CH}\right)$ situated on $\alpha$ and $\beta$ states in respect of the aromatic nuclears.

The analysis of the results presents that the structure of the I fraction average molecule (before the purification) consists of 3 and 4 cyclic naphthene rings $\left(\mathrm{K}_{\mathrm{H}}=3.73\right)$ and it may be imagined as condensed by aromatic structures $\left(\mathrm{K}_{\mathrm{A}}=0.40\right)$. The share of carbon atoms in naphthene $\left(\mathrm{C}_{\mathrm{N}}\right)$ and alkyl $\left(\mathrm{C}_{\text {alk }}\right)$ structures consists of $\sim 59 \%$ and $\sim 24 \%$ correspondingly.

The basic parameters in $\mathrm{I} \rightarrow \mathrm{I} \rightarrow \mathrm{II} \rightarrow \mathrm{IV}$ are changed in naphthene hydrocarbons favor after the purification and they exceed other structural fragment $\left(C_{N}\right.$ increases from $\sim 58.6 \%$ up to $\left.\sim 79.4 \%\right)$.

Aromatic hydrocarbons share is nearly $0\left(C_{A}=0.02 \%\right)$, but alkyl fragments are reduced $\left(C_{\text {alk. }}\right.$ from $24 \%$ to $\left.20 \%\right)$.

Tricyclic naphthenes mostly exceed in the fractions compositions. But tetracyclic naphthenes aren't more than $\sim$ $10 \%$. 


\section{CONCLUSIONS}

As a result of the investigations it has been determined that although long contacting duration and wide temperature range of Naphthalane oil with IL-morpholinephormiate, there isn't any positive impact on the percentage amount of aroatic hydrocarbons in the raffinate. And also percentage amount of aromatic hydrocarbons of the raffinates obtained by the purification of Naphthalane oil fraction through $\mathrm{N}$-methyl-2-pyrrolidon has seriously minimized in comparison with ILmorpholinephormiate. Thus, the raffinates purified by N-methyl-2-pyrrolidon have been studied by NMR-, UV- and IRspectrophotometer methods. As the affirmative results residue amount of the aromatic hydrocarbons of the raffinates (UVmethod) at $1: 2.5,1: 3$ is $1.5 \%, 2 \%$ correspondingly, but sulfur amount is $0.012 \%$ and $0.011 \%$. Simultaneously, the raffinates purified by $\mathrm{N}$-methyl-2-pyrrolidon has been passed on the adsorbent for a time. The molecular weight of the raffinate obtained is reduced from 268 down to 249, from 258 down to 246, and percentage amount of aromatic hydrocarbons - from $2 \%$ down to $0.07 \%$, from $1.5 \%$ down to $0.02 \%$.

As a result of the investigations percentage amount of naphthene hydrocarbons in theraeputic Naphthalane oil fractions samples has increased from $58.6 \%$ up to $79.4 \%$, reflecting vitally important and theraupeutic properties for human organism.

As the final result we may say that the selective purification and adsorbtion method studied by us can be considered the most successful and perspective purification method for theraupeutic Naphthalane oil. The experimental results proves it visually, too.

1) Naphthalane oil fraction boiling at $260-340^{\circ} \mathrm{C}$ has been studied by spectroscopic methods (NMR-, UV-, IR) before and after the purification.

2) It has been determined that as carcinogenics it's possible to minimize aromatic hydrocarbons amount in the fraction using these methods.

3)The results allow wide usage of purified Naphthalane oil fraction samples for medicine and cosmetics industry.

Thus, we produce environmentally-friendly, non-waste, having high therapeutical properties white Naphthalane oil without using any catalyst, pressure, adsorbent and acid by energy-saving methods.

\section{REFERENCES}

1. A.M. Kuliyev, A.A. Petrov, A.M. Levshina. et al. Some Peculiarities of Structure of Naphthene Hydrocarbons of Naphthalane Oil. // Azerbaijan Oil Industry, 1970, № 3, p. 44-49.

2. M.F. MirBabaev, F.I. Samedova. Structural Peculiarities of High-Molecular Compounds of Naphthalane Therapeutic Oil. // Azerbaijan Oil Industry, 1991, № 4, p.49-52.

3. L.M. Polyakova, S.I. Djafarov,V.A. Adigezalova et.al. Chemical composition \&Properties of oils of different horizons of Naphthalane field, Ufa, Publish. House "Reaktiv". 2001. 124 p.

4. V.M. Abbasov, L.I. Aliyeva, G.A. Najafova, B.M. Aliyev, P.A. Movsumova. Dearomatization of Fr. $260-340^{\circ} \mathrm{C}$ of Medical Naphthalane Oil with N-methyl-2-pyrrolidon. // World of Oil Products. The Oil Companies Bulletin, 2013, № 5, p. 35-39.

5. R.D. Rogers, K.R. Seddon. Ionic Liquids. Industrial Applications to Green Chemistry. // ACS Symposium Series 818, American Chemical Society, Washington, DC, 2002.

6. P. Wasserscheid, T. Welton. Ionic Liquids in Synthesis. /Wiley-VCH Verlag, 2002.

7. N.V. Ignatyev, U. Ves-Birman, H. Vilner. New Perspective lonic Liquids. //Russian Chemical Journal, 2004, vol. XLVIII, № 6 .

8. V.F. Kamyanov, G.F. Bolshakov. Definition of Structural Parameters by Structural-Group Analyses of Oil Components. //Petrochemistry, 1974, vol. 24, № 4, p. 450. 